\title{
O espaço, o drama: vida pública e cenas urbanas do Rio de Janeiro
}

Rafael Augusto Andrade Gomes

Universidade Federal do Rio de Janeiro. Programa de Pós-Graduação em Geografia. Instituto de Geociências. Rio de Janeiro, Brasil.

Recibido: 3 de diciembre de 2020. Aceptado: 26 de marzo de 2021.

\begin{abstract}
Resumo
Nos parágrafos seguintes, discutirei, à luz de episódios da história do Grupo de Pesquisa Território e Cidadania, o conteúdo do livro Formas de la Sociabilidad. Una geografía de los espacios públicos en Río de Janeiro, organizado por Paulo Cesar da Costa Gomes e Leticia Parente Ribeiro, ambos docentes da Universidades Federal do Rio de Janeiro e coordenadores do referido grupo de pesquisa em 2019. Este artigo nasceu, em parte, como uma resposta à seguinte questão: como foram desenvolvidos os conceitos e procedimentos metodológicos das pesquisas cujos resultados foram coligidos no livro em questão? A história de um livro, segundo a hipótese que orienta este trabalho, está intrincada com a história de uma série de pesquisas que o antecederam. Portanto, para responder à pergunta de pesquisa, e em alusão às divisões de uma peça teatral, o texto apresenta em três atos a mudança progressiva nos temas e estratégias de investigação dos integrantes do Grupo de Pesquisa Território e Cidadania ao longo de duas décadas, com ênfase na produção científica de Paulo Cesar da Costa Gomes, seu mais longevo coordenador. Por fim, o último ato contém uma caracterização de cada um dos capítulos do Formas de la Sociabilidad, que, em linhas gerais, compõem um amplo projeto para o conhecimento geográfico dos espaços públicos.
\end{abstract}

PALAVRAS-CHAVE: ESPAÇO PÚBLICO. CIDADANIA. GEOGRAFIA. CENÁRIO. SOCIABILIDADE.

\section{The space, the drama: public life and urban scenes in Rio de Janeiro}

\begin{abstract}
In the following paragraphs I will discuss, in the light of episodes of the history of the Territory and Citizenship Research Group, the content of the book Formas de la Sociabilidad. Una geografía de los espacios públicos en Río de Janeiro published in 2019 by Paulo Cesar da Costa Gomes and Leticia Parente Ribeiro, both professors at the Federal Universities of Rio de Janeiro and coordinators of that research group. This text was born, in part, as an answer to the following question: how the concepts
\end{abstract}


0 espaço, o drama: vida pública e... RAFAEL AUgusto ANDRADE Gomes

and methodological procedures collected in the book were developed? The history of a book, according to the hypothesis that guides this work, is intricate with the history of a series of studies that preceded it. Therefore, to answer the research question, and in allusion to the divisions of a play, the text presents in three acts the progressive change in the themes and research strategies of the members of the Territory and Citizenship Research Group over two decades, with emphasis on the scientific production of Paulo Cesar da Costa Gomes, its longest-lived coordinator. Meanwhile, the last act contains a characterization of the chapters of Formas de la Sociabilidad which, in general, compounds a broad project for the geographical knowledge of public spaces.

KEYWORDS: PUBLIC SPACE. CITIZENSHIP. GEOGRAPHY. SCENERY. SOCIABILITY.

PALABRAS CLAVE: ESPACIOS PÚBLICOS. CIUDADANÍA. GEOGRAFÍA. ESCENARIO. SOCIABILIDAD.

\section{Prelúdio}

Em 1962, John Kirtland Wright (1891-1969), então geógrafo e bibliotecário aposentado da American Geographical Society, publicou um estudo sobre o livro Influences of Geographic Environment, On the Basis of Ratzel's System of Anthropo-Geography (Semple, 1911). Com esse estudo -cuja primeira versão fora preparada por John Wright a pedido de Preston James (1899-1986), em 1961, e apresentada na reunião anual da Association of American Geographers (AAG) antes de aparecer nas páginas do periódico Geographical Review (Wright, 1962)-, o autor propõe a realização de uma bibliobiografia $^{1}$ do referido livro de Semple. Um dos pressupostos da pesquisa de Wright (1962), desenvolvido por Hartshorne (1979) anos depois, é de que, tal como as pessoas, alguns livros merecem biografias (às biografias de livros o autor propõe a denominação bibliobiografia). ${ }^{2}$

De acordo com Wright (1962), pelo menos no caso de livros que não apresentam mudanças no conteúdo textual, como supostamente era o livro de Semple (1911), a bibliobiografia consiste no "registro, análise e interpretação de mudanças nos usos e efeitos do livro e nas atitudes dos leitores em relação a ele" (Wright, 1962:350, tradução livre). ${ }^{3}$ Assim sendo considerada, a biografia do livro teria início no instante de sua publicação. Sabemos, no entanto, que, apesar de a existência material ser um marco fundamental na história de um livro, a trajetória de sua vida também pode ser narrada a partir das condições de sua produção ou concepção. Publicado quase 60 anos depois do artigo de Wright (1962), a história do livro ora comentado, intitulado Formas de la Sociabilidad. Una geografía de los espacios públicos en Río de Janeiro (Gomes e Parente-Ribeiro, 2019), antecede o ano de sua publicação. Veremos alguns episódios dessa história antes de passar a limpo o conteúdo do livro, que faz parte da Colección Eirene, do Instituto de la Paz y los Conflictos (Universidade de Granada, Espanha), dirigida por Carmen Egea Jiménez.

\footnotetext{
1 Do original, em inglês: bibliobiography.
}

2 Em contraste com a biobibliografia (em inglês: biobibliography), termo usual para designar "uma mescla da vida do indivíduo com sua contribuição científica (geralmente na forma de publicações)" (Armstrong e Martin, 2000:257), a bibliobiografia privilegia a "história de vida" do livro em detrimento da biografia de seu autor.

3 Em 2010, pouco menos de 50 anos depois da publicação de Wright (1962), Keighren (2010) desenvolve um programa de pesquisa bibliobiográfico de Semple (1911). Keighren (2010), amparado pelos estudos recentes em geografia da ciência e da leitura, investiga a recepção do livro de Semple (1911) em diversos momentos, lugares e tradições disciplinares. 
0 espaço, o drama: vida pública e... RAFAEL AUgusto ANDRADE GOMES

\section{Ato 1: Entre território e cidadania}

Organizado por Paulo Cesar da Costa Gomes e Leticia Parente Ribeiro (2019), ambos docentes do Departamento de Geografia da Universidade Federal do Rio de Janeiro (UFRJ), o livro Formas de la Sociabilidad. Una geografía de los espacios públicos en Río de Janeiro (doravante Formas de la Sociabilidad) reúne 14 artigos de colaboradores do Grupo de Pesquisa Território e Cidadania divididos em quatro partes: 1) superfícies; 2) ocupações; 3) descontinuidades, 4) estranhezas. A obra consiste, em conjunto com seus três textos de apresentação, num mosaico de cenas urbanas da cidade do Rio de Janeiro. ${ }^{4}$ Não foi por acaso que utilizamos a palavra cena. Tal conceito, o de cena, ou cenário, corresponde a um dos tantos princípios teórico-metodológicos desenvolvidos por Gomes (2008a, 2013), Gomes e Parente-Ribeiro (2013) e Parente-Ribeiro (2016) para a investigação geográfica dos espaços públicos a partir de imagens. Espaço público e imagem. Para entender o significado do encontro entre essas duas expressões na obra dos autores, é preciso voltar ao passado em algumas décadas.

Após uma série de aulas, reuniões e seminários na França, entre 1993 e 1994, o geógrafo Paulo Cesar da Costa Gomes retorna ao Brasil com uma bolsa de recém-doutor do Conselho Nacional de Desenvolvimento Científico e Tecnológico (CNPq) para realizar pesquisas no Programa de Pós-Graduação em Geografia da UFRJ. No ano seguinte, depois de aprovado num concurso para docente permanente do Departamento de Geografia da UFRJ, ele inicia a constituição do Grupo de Pesquisa Território e Cidadania. O nome do grupo deriva de sua hipótese de pesquisa à época: "apesar do pouco relevo explícito da questão territorial no discurso de alguns especialistas sobre a questão da cidadania, o território, sua dinâmica, sua configuração, sua constituição e natureza são assinalados como elementos fundamentais na redefinição das relações políticas" (Gomes, 1997:45).

O mundo antigo, sobretudo greco-romano, e a Europa das revoluções burguesas no século XVIII são os momentos e lugares privilegiados por Gomes $(1997,2001 \mathrm{a}) \mathrm{em}$ sua hipótese de que a democracia e a cidadania, em todos os ângulos possíveis, estão associadas a dinâmicas territoriais. Durante as reformas de Clístenes (565 a.C.- 492 a.C.) na Grécia Antiga, houve a "substituição da representação política baseada nas tribos gentílicas por uma representação de base espacial, ou seja, por uma divisão territorial e não mais por uma divisão que respeitasse as fronteiras sanguíneas" (Gomes, 1997:44). De acordo com esse ponto de vista, a polis, a cidade grega, consiste na estrutura espacial correspondente à organização social do regime democrático. A ancestralidade sanguínea constituinte dos genos, na Grécia reformada de Clístenes, dá lugar à polis democrática -o cidadão, indivíduo livre da polis, é definido a partir dos limites de um território-.

Sabe-se que Paulo Cesar Gomes, em publicação posterior (Gomes, 2001a), baseado na definição estabelecida por Robert Sack (1986) em Human Territoriality - Its theory and history, definiu o território como uma porção física do espaço "mobilizada como elemento decisivo no estabelecimento de um poder. Ela é assim uma parcela de um terreno utilizada como forma de expressão do controle sobre outrem" (Gomes, 2001a:12). O território,

4 Há três textos de abertura no Formas de la Sociabilidad (Gomes e Parente-Ribeiro, 2019): 1) prólogo assinado por Daniel Hiernax-Nicolas; 2) uma apresentação escrita por Juan Luis de las Rivas Sanz; 3) a introdução dos organizadores, Paulo Cesar da Costa Gomes e Leticia Parente Ribeiro. 
0 espaço, o drama: vida pública e...

segundo Gomes (2001a), não se confunde com a identificação, tampouco com a simples delimitação de áreas num mapa; pelo contrário, a conversão de uma área em território somente é possível com a "imposição de regras de acesso, de circulação e a normatização de usos, de atitudes e comportamentos sobre este espaço" (Gomes, 2001a:12).

Voltemos à Antiguidade Ocidental mais uma vez. Antes de fazer referência à forma da clássica cidade grega, a palavra polis, originalmente, "tinha a conotação de algo como "muro circundante"' (Arendt, 2007:73). A organização da polis grega, portanto, dependia de um substrato físico, delimitado por muros, e, além disso, de leis que garantissem a vida política. A mesma organização pode ser encontrada na cidade ou urbs romana. A própria palavra urbs, por derivar da mesma raiz latina que orbis, exprimia uma noção de círculo ou circunferência (Arendt, 2007:73). Na Roma Antiga, o pomerium (contração da frase pós moerium, que significava após o muro), ou seja, o muro fronteiriço das cidades, estabelecia o alcance territorial dos comportamentos admitidos no interior de seus limites (Gomes, 1997). Como exemplo disso, com base mais uma vez em Gomes (1997), é possível citar a proibição generalizada do porte de armas no interior dos limites definidos pelo pomerium. Tudo o que foi dito acima sobre a polis e a urbs, a despeito das inumeráveis distinções entre gregos e romanos no estabelecimento das leis e das cidades, esclarece como o conceito de território empregado por Gomes (2001a) servia à designação de uma área cuja delimitação física também definia um conjunto de comportamentos associados.

O que foi exposto acima é suficiente para demonstrar que, a cada momento histórico, à estrutura física das cidades se associa um sistema de ações e condutas dos cidadãos. Não bastava colocar um limite físico para distinguir entre a área da cidade e seu entorno. Como ressalta Arendt (2007), ao menos em relação à concepção grega das leis, o legislador, tal qual o arquiteto responsável pela fabricação dos muros, era um artesão: ambos, arquiteto e legislador, "pertenciam à mesma categoria" (Arendt, 2007:207). Não cabe aos nossos propósitos neste texto realizar uma excursão histórica às interações entre território, democracia e cidadania no Ocidente -que, apesar de fundadas na Antiguidade greco-romana, foram remodeladas na Europa iluminista-. Por isso, mais uma vez, sigamos o exemplo das cidades gregas clássicas. Os limites das cidades-estados da Grécia Antiga, como vimos, definiam o conteúdo e alcance da cidadania. Mas e a vida humana no interior da polis? É possível afirmar que, além da distinção entre o interior e o exterior da cidade, a fundação da polis correspondeu ao estabelecimento de duas esferas intramuros: a pública e a privada.

A distinção entre as esferas pública e privada "corresponde à existência das esferas da família e da política como entidades diferentes e separadas, pelo menos desde o surgimento da antiga cidade-estado" (Arendt, 2007:21). Em outras palavras, com a ruptura das unidades baseadas no poder dos genos, ou seja, das formas de controle e gestão pautadas em solidariedades ancestrais, parentais ou consanguíneas, o cidadão recebera, além da vida privada com base na casa (oikos), "uma espécie de segunda vida, o seu bios politikos. Agora cada cidadão pertence a duas ordens de existência" (Arendt, 2007:33). Em contraste com a família, que se organizava fundamentalmente a partir da desigualdade entre seus membros, a polis, apesar de reunir pessoas tão distintas umas das outras dentro dos limites de seus muros, reconhecia os cidadãos como "iguais". Para que o cidadão grego pudesse viver essa nova ordem de existência, o bios politikos, emergiu também um novo tipo de espaço na polis: o espaço público. 
0 espaço, o drama: vida pública e... RAFAEL Augusto ANDRADE Gomes

\title{
Ato 2: Espaços, culturas e cenas da vida pública
}

\begin{abstract}
Aos sábados pela manhã, não sou, conscientemente, um geógrafo. Como tantas outras pessoas da minha idade e estilo de vida, devo ser encontrado fazendo compras com minha família no meu centro habitual de compras (...) / Então, compreendo que outras coisas também estão ocorrendo: pedem-me para contribuir para uma causa que eu não aprovo; viro a esquina e vejo um cristão evangélico idoso distribuindo folhetos. O principal espaço aberto está ocupado por uma vitrine de painéis para melhorar a insolação das casas -ou, em minha opinião, a harmonia visual da minha rua. Ao redor da base de concreto da árvore decorativa, um grupo de adolescentes com cortes de cabelo moicano vividamente coloridos e faixas de tachas no braço olha com desdém os consumidores de meia-idade (...) / O local é, então, altamente complexo, com múltiplos patamares de significados. / (...) O local é um lugar simbólico, onde muitas culturas se encontram e, talvez, entrem em conflito (Cosgrove, 2012:219-220).
\end{abstract}

Afinal, o que são os espaços públicos? Como estudá-los a partir de uma perspectiva geográfica? Vimos, até aqui, que o percurso das investigações de Paulo Cesar Gomes -e, por consequência, dos integrantes do Grupo de Pesquisa Território e Cidadania, pelo menos até o início dos anos 2000-, baseava-se no conceito de território. A partir desse conceito, deu-se continuidade à inclusão da cidadania moderna no temário de pesquisas da geografia brasileira, cujo impulso anterior havia sido dado por Milton Santos (1987) no livro $O$ Espaço do Cidadão. Mas será necessário extrapolar as "operações executadas pelo conceito de território" (Gomes, 2020:157) para que compreendamos a variedade dos espaços públicos das cidades contemporâneas. Para Gomes (2001b:94), os espaços públicos se estruturam, "primeiramente, pela aplicação de diferentes regras que classificam e hierarquizam os diferentes territórios”; porém, como discutido a partir do exemplo grego, a lei não é suficiente para definir o espaço público.

Já na própria constituição do espaço público na Antiguidade Ocidental, como dissemos, encontra-se a necessidade de união entre uma dimensão formal, prevista e normatizada pela lei, e outra relativa aos comportamentos individuais. O espaço público, portanto, dependerá de um lugar físico e de um repertório de práticas e comportamentos para existir como lócus da vida democrática (Gomes, 2001a; Gomes, 2001b). As palavras civilidade, cortesia e polidez, por exemplo, designam uma parte ou o conjunto das atitudes e comportamentos que os cidadãos adotam nas relações que estabelecem entre eles nas cidades modernas. Nesse sentido, é especialmente relevante a significação do termo "público", que, além de denotar tudo o que "pode ser visto e ouvido por todos e tem a maior divulgação possível” (Arendt, 2007:59), também é utilizado para designar "o próprio mundo, na medida em que é comum a todos nós" (Arendt, 2007:62). ${ }^{5}$

Para convivermos no mundo, completa Arendt (2007:62), é necessário que haja, tal como a mesa interposta entre os indivíduos, um intermediário que separe e possibilite as relações entre as pessoas: "essa mesa é o espaço público, aquilo que reúne e separa, que iguala e diferencia” (Gomes, 2020:161). Para fundamentar seu argumento de que o

5 Essa significação de público se assemelha à ideia de publicidade, tal como fora forjada na Europa do século XVIII, como o conjunto de fenômenos que se apresenta aos outros no mundo comum (Gomes, 2008a; Gomes, 2020). 
0 espaço, o drama: vida pública e...

espaço público é a mesa entre os cidadãos nas sociedades democráticas, Gomes (2001b; 2008a; 2012) se vale diretamente da noção de "forma-conteúdo" (Santos, 1978) ou, ainda, da compreensão de que o espaço se constitui a partir de um "conjunto inseparável de sistemas de objetos e sistemas de ações" (Santos, 2012 [1996]:103). Resulta disso a necessidade de considerar, numa investigação geográfica, o caráter híbrido do espaço público sobre o qual já discorremos linhas acima: 1) por um lado, é um espaço dotado de objetos, corpos e formas numa composição física, material; 2) por outro lado, é o terreno que abriga um conjunto de práticas, ações e relações sociais na vivência cotidiana desses espaços.

Assim, o espaço público, qualquer que seja sua configuração física (a rua de uma grande cidade, por exemplo), também encerra em seus limites um tipo geral de comportamento, um tipo de cultura: a cultura pública (Gomes, 2001b; Gomes, 2008a). A palavra cultura ${ }^{6}$ destaca, sobretudo, o caráter comunicacional das ações individuais apresentadas no espaço público -a comunicação e o debate lógico-racional, aliás, formam a base das contribuições de Jürgen Habermas (1929-presente) à definição de "esfera pública" nas ciências sociais desde os anos 1960-. Não é necessário que entremos em detalhes na teoria da ação comunicativa e sua relação com a esfera pública, conforme desenvolvido por Jürgen Habermas; porém, é preciso destacar a especificidade dos comportamentos e atitudes apresentados em público. Como nos ensina, mais uma vez, Arendt (2007:56), "o fato de uma atividade ocorrer em particular ou em público não é, de modo algum, indiferente. (...) o caráter da esfera pública muda segundo as atividades que nela são admitidas, mas, em grande parte, a natureza da própria atividade também muda”. Num raciocínio paralelo ao de Arendt (2007), o espaço público, se concebido como mediador das relações entre as pessoas no cotidiano de sociedades democráticas, mudará conforme os comportamentos daqueles que o ocupam; tais comportamentos, por sua vez, não passarão incólumes à sua aparição em público.

Os trechos citados por extenso na epígrafe desta seção fazem parte do texto A geografia está em toda parte: cultura e simbolismo nas paisagens humanas (Cosgrove, 2012 [1989]). Em tais fragmentos, Denis Cosgrove (1948-2008), geógrafo britânico com larga contribuição no uso de imagens em geografia, descreve a variedade de grupos e atividades que ocupam os espaços públicos de um centro comercial na Inglaterra. Num mesmo lugar, e em apenas um instante, estão reunidos consumidores de classe média de meia-idade, idosos evangélicos distribuindo folhetos religiosos e adolescentes de uma tribo urbana qualquer, provavelmente a punk, que se difundira na Inglaterra na década anterior à redação do texto de Cosgrove (2012 [1989]). Cada um desses grupos possui estratégias de apresentação ao público e, em algumas situações, de imposição do seu domínio sobre extensões espaciais da cidade. Em casos assim, nos quais determinados grupos desenvolvem estratégias para dominar outrem a partir do controle de uma extensão espacial, ou, ainda, para obter o uso exclusivo de uma determinada área, o conceito de território parece oferecer um ângulo razoável de análise dos espaços públicos.

6 A conexão entre cultura e mundo público também foi destacada pelo antropólogo Clifford Geertz (2008 [1973]:9): "A cultura é pública porque o significado o é. Você não pode piscar (ou caricaturar a piscadela) sem saber o que é considerado uma piscadela". É verdade que a noção de público, em Geertz (2008 [1973]), está mais próxima da ideia geral de atitudes com significados compartilhados por indivíduos de um determinado grupo do que da definição histórica que expusemos na segunda seção deste texto. 
0 espaço, o drama: vida pública e... RAFAEL AUgusto ANDRADE GoMES

No entanto, por estarem fundados em um estatuto jurídico igualitário e democrático, os espaços públicos podem comportar simultaneamente grupos e indivíduos com interesses e expectativas bastante variados, às vezes mesmo antagônicos. Cumpre, pois, observar que os espaços públicos são, de um lado, constituídos pela lei e, de outro, animados cotidianamente como "um espaço de livre acesso a todos, de ritualização da vida social, em grande parte devido ao comportamento daqueles que [o] utilizam" (Gomes, 2001b). Em outras palavras, os espaços públicos são espaços regulados por normas que garantem a coabitação pacífica dos indivíduos e, ademais, espaços nos quais são apresentados comportamentos que os identificam à vida pública e democrática (Gomes, 2001b; Gomes, 2004). Ainda que tenhamos formas urbanas frequentemente concebidas como sinônimas dos espaços públicos em uma determinada cidade (praças, ruas ou outros logradouros públicos), quando grupos ou indivíduos adotam estratégias de dominação dessas áreas, o estatuto público é suspenso.

Começamos este texto apresentando a relevância da dimensão territorial na cidadania moderna para a definição da agenda de investigações geográficas de Paulo Cesar Gomes e do Grupo de Pesquisa Território e Cidadania. Vimos também que a reorganização das relações políticas, ocorrida na cidade-estado grega reformada por Clístenes, ocasionou o surgimento de uma nova ordem de existência dos indivíduos em sociedade, o bios politikos, e de um espaço para o exercício da vida cidadã, o espaço público. Esse tipo de espaço se estrutura graças à combinação de três atributos: 1) normas que garantem a coabitação democrática e estabelecem a isonomia dos cidadãos; 2) uma configuração material, ou seja, um lugar físico; 3) comportamentos e interações sociais. Ao observar atentamente os espaços públicos de uma cidade, mesmo que os três ingredientes estejam presentes, percebemos que alguns deles "parasitam a 'cena' pública, monopolizam a expressão da vida urbana em determinados centros” (Gomes, 2008a:190). Por vezes, determinados espaços públicos funcionam como metonímias da cidade. É o caso, por exemplo, das praias da Zona Sul da cidade do Rio de Janeiro, que atualmente são centrais no imaginário ${ }^{7}$ associado à identidade carioca.

Antes de continuar, porém, faz-se necessária uma observação. O reconhecimento de lugares que concentram a vida pública das cidades, ou seja, os ritos sociais indispensáveis à coabitação democrática dos indivíduos, é menos absoluto do que demos a entender. Portanto, os mesmos lugares, a exemplo das praias do Rio de Janeiro, apresentam diferenciações internas relativas à frequência e aos ritmos de ocupação, aos tipos de atividades, à faixa etária dos frequentadores, entre outras tantas características que dão vida aos espaços públicos no cotidiano das cidades. Isso significa, então, que uma superfície contínua, como uma praia, provavelmente abrigará os distintos resultados das combinações entre as formas físicas e os comportamentos dos cidadãos. Inversamente, áreas aparentemente apartadas umas das outras, quero dizer, fragmentadas fisicamente ou separadas por diferentes estatutos jurídicos, podem se associar a partir de alguma das dinâmicas da cena pública. É o caso de alguns bares, restaurantes ou outros estabelecimentos quando projetam suas atividades sobre os logradouros públicos adjacentes.

7 A expressão imaginário não possui uma significação consensual nas ciências sociais. Apesar de todas as controvérsias sobre o seu conteúdo, utilizamo-la de acordo com Gomes (2017:141), que concebe o imaginário como "um conjunto articulado de inúmeras cenas, de relações e fluxos, no qual a sucessão de imagens produz sentidos diversos e arranjos de significação intercambiáveis". 
Diante de tudo o que foi exposto até aqui, poder-se-ia perguntar: como investigar, a partir de um ponto de vista geográfico, esses espaços que concentram a vida pública nas cidades? Seriam os ângulos de pesquisa abertos pelo conceito de território, como foram nos textos inaugurais de Gomes (1997; 2001a; 2001b) sobre o inextricável caráter geográfico da cidadania moderna, compatíveis com a vivência cotidiana dos espaços públicos? Como assinalamos na seção anterior, o território -bem como sua principal operação conceitual, a concepção de que uma porção de área se encontra sob controle ou em disputa por indivíduos ou grupos sociais- não esgota as possibilidades de investigação dos espaços públicos. Sabemos, e este fato é bastante perceptível em suas publicações, sobretudo a partir do início dos anos 2000, que o conceito de território perde progressivamente a importância de outrora nas pesquisas de Paulo Cesar Gomes. E, embora a questão anunciada no início deste parágrafo (sobre a abordagem geográfica dos espaços públicos) permaneça sem resposta definitiva até os dias de hoje, ela ensejou a elaboração de uma proposta conceitual (Gomes, 2008a) e a profusão de exercícios metodológicos no âmbito do Grupo de Pesquisa Território e Cidadania.

\section{Ato 3: Cenário: conceito e exercícios metodológicos}

Pouco mais de oito anos depois de sua fundação, formou-se, no interior do Grupo de Pesquisa Território e Cidadania, um ambiente favorável ao estudo do uso das imagens na ciência geográfica e à pesquisa baseada em metodologias visuais. Como questiona Gomes (2008a), em texto que se originou de uma comunicação apresentada no V Simpósio Internacional sobre Espaço e Cultura, realizado em 2006, no Rio de Janeiro: de que maneira é possível interpretar as imagens a partir de um ponto de vista geográfico? Deve-se, antes de ensaiar uma resposta, atentar para uma definição preliminar de "imagem". As imagens, reforça o autor, "são produtos quase exclusivamente visuais, pelo menos esse sentido tem preeminência absoluta sobre qualquer outro dentro da cultura ocidental" (Gomes, 2008a:191). Mais que isso, a imagem "pertence ao domínio da representação" (Gomes,2008a:192).

Segundo o autor, essa compreensão da imagem como representação dividiu, e por vezes ainda divide, o debate em duas posturas extremas. Uma realista, na qual a imagem é concebida como uma cópia ou espelho da realidade e sua qualidade aumentaria à medida da proximidade com o real -em tal postura, a imagem é um "documento fidedigno", uma evidência da realidade-; e outra idealista, na qual as imagens "não espelham o mundo, elas o criam" (Gomes, 2008a:192). Em contraste com a primeira, na postura idealista, a realidade é compreendida como um produto das nossas mentes, cujo acesso somente é possível por intermédio das representações. Diante da esterilidade dos debates ensejados pela ambiguidade dessas posturas, Paulo Cesar Gomes cultivou o ambiente de estudos do Grupo Território e Cidadania, no início dos anos 2000, com a discussão semanal de textos de intelectuais que desenvolveram sistemas de interpretação das imagens -entre eles Erwin Panofsky (1892-1968), Roland Barthes (1915-1980) e Ernst Gombrich (1909-2001)-.

Deve-se acrescentar que, a partir de 2004, o interesse de Paulo Cesar Gomes pelas imagens se faz visível não apenas em sua produção acadêmica escrita, mas no temário abrangido por monografias de conclusão de graduação, dissertações de mestrado e teses de doutorado defendidas sob sua supervisão no Departamento de Geografia da UFRJ 
0 espaço, o drama: vida pública e... RAFAEL AUgusto ANDRADE Gomes

desde então (Santos, 2004, 2007; Silva, 2004, 2007; Valverde, 2007; Góis, 2008). ${ }^{8}$ Vale ressaltar, no mesmo período, as disciplinas por ele ministradas no curso de graduação em geografia da UFRJ: um curso de Metodologia Científica, cujo objetivo era discutir, baseado em filmes, procedimentos metodológicos da pesquisa em geografia (como o trabalho de campo); um curso de Geo-história inteiramente estruturado a partir de narrativas fílmicas; um curso de Geografia e Cinema, no qual os alunos eram incitados a discutir e analisar filmes de um ponto de vista geográfico (Gomes, 2011a).

Entre 2004 e 2005, além da pergunta inicial -"Como operacionalizar o trabalho com imagens na geografia (...) sem apenas tomá-las como ‘aparências'?” (Gomes, 2011a:11)-, afigura-se, para Paulo Cesar Gomes e os demais integrantes do Grupo de Pesquisa Território e Cidadania, a necessidade de se perguntar sobre a maneira de "trabalhar geograficamente com imagens em movimento" (Gomes, 2011:12). Há, entre os geógrafos, observa Gomes (2008a; 2011a), o uso frequente das imagens apenas para ilustrar e acompanhar conclusões a que o pesquisador já havia chegado por outros meios -como o discurso verbal-. As imagens, nesse caso, são secundárias e estão justapostas ao texto, a suposta fonte do raciocínio, das explicações e das conclusões de uma pesquisa. Como trabalhar com as imagens sem relegá-las a uma posição secundária, ou seja, sem utilizá-las apenas como ilustração de argumentos textuais?

Para responder a essas questões, no ano de 2006, em evento na Universidade do Estado de Rio de Janeiro, Paulo Cesar Gomes propõe o conceito de cenário na análise de imagens em geografia (Gomes, 2008a; Gomes, 2008b). Um aspecto importante a considerar, no caso da elaboração do conceito de cenário, é que ele foi desenvolvido no interior de um programa de pesquisas sobre os espaços públicos. O conceito de cenário, segundo o autor, foi elaborado inicialmente para possibilitar a análise das imagens sequenciais dos espaços públicos, a cena pública, concebida como uma "sequência ininterrupta de eventos, com garantida comunicabilidade relacionada à morfologia $\mathrm{e}$ ao estatuto [público] desses espaços e através dos quais são construídos e transmitidos significados públicos" (Gomes, 2011a:13). Embora o conceito de cena, ou cenário, faça uma explícita alusão ao cinema e ao teatro, Gomes e Góis (2008) utilizaram-no para investigar a representação das cidades nas histórias em quadrinhos. Afinal, quais são as bases do conceito de cenário?

A palavra cenário indica a reunião da "ação e do lugar da ação dentro de uma mesma unidade, partindo do princípio de que a significação das imagens é o resultado dessa compósita integração" (Gomes, 2011a:14). Essa indicação deriva, por sua vez, da etimologia e dos diversos sentidos atribuídos à palavra cenário em alguns idiomas, cujo significado variará entre "o espaço da encenação", ou seja, ao lugar da cena no teatro, e o "enredo ou argumento de uma peça ou de um filme" (Gomes, 2008a:199). ${ }^{9}$ Segundo Gomes (2008a), apesar de derivadas da mesma palavra latina (scaenarium), a palavra cenário em português e em francês possui significados bastante distintos. Em português, ela é utilizada para caracterizar a configuração física de um dado lugar, que abrigará

8 Com exceção das dissertações de mestrado e teses de doutorado, que estão disponíveis em formato digital no repositório do Programa de Pós-Graduação em Geografia da UFRJ, alguns desses trabalhos, particularmente as monografias, são documentos de difícil acesso.

9 Correspondente à primeira acepção, de lugar da cena, é possível citar a palavra latina scaenarium. Em contraste com a acepção latina, ressalta Gomes (2008a), a palavra francesa scénario designa o enredo de uma ação dramática no teatro ou no cinema. 
0 espaço, o drama: vida pública e... RAFAEL AUgusto ANDRADE Gomes

práticas, eventos e comportamentos. Portanto, o lugar no qual ocorrerá a ação dramática. Em francês, por outro lado, a palavra (scénario) é utilizada para designar as ações e o conjunto de acontecimentos do enredo de uma narrativa fílmica ou teatral. Esses exemplos bastam, sem dúvida, para embasar o objetivo de Gomes (2008a) ao reunir as formas materiais às ações e comportamentos figurados e, a partir dessa composição, interpretar as suas significações.

Não é possível inferir disso, de maneira sumária, que as cenas dos espaços públicos e do cinema ou teatro sejam homólogas. No cinema e no teatro, a composição dos cenários, isto é, a integração entre as formas físicas e os comportamentos, é roteirizada. O público, ou como também se diz, a plateia, de uma apresentação teatral ou de uma projeção cinematográfica interpreta as imagens de acordo com sua colocação numa montagem -uma sequência, frequentemente cronológica, de apresentação dos cenários-. O sentido de uma imagem, portanto, é depreendido pelo público de acordo com a ordem narrativa da apresentação estabelecida por um demiurgo. O mesmo não acontece na vida cotidiana nos espaços públicos das cidades contemporâneas. "Não há uma finalidade na vida social de todos os dias" (Gomes, 2008a:204).

Também não há, completa Gomes (2008a), um roteirista da vida social organizando as formas, os comportamentos, os figurinos e os modos de interação entre os personagens na cena pública. O mesmo acontece com a distinção entre "palco" e "plateia". Mesmo que um pesquisador, por exemplo, vá às ruas com o objetivo de observar as cenas que se apresentam, ele participará do espetáculo, comporá um cenário no qual a sua "ação se soma a muitas outras e produz efeitos inesperados e não dirigidos. Os espetáculos da vida social se sobrepõem sem que necessariamente possuam coerência entre si, sendo múltiplos, variados" (Gomes, 2008a:205-206). O pesquisador, que observa, também é observado pelos demais cidadãos e interfere na composição da cena. ${ }^{10} \mathrm{Se}$ não há roteiro, e se os cenários são tão diversos, é possível afirmar que as chaves de interpretação dos espaços públicos a partir de imagens não estão dadas de antemão. Desde então, o conceito de cenário, assim como a pesquisa com imagens, tem orientado as pesquisas e atividades do Grupo de Pesquisa Território e Cidadania. A seguir, apresentaremos algumas delas.

Aqui, antes de continuar, podemos recapitular a ordem dos acontecimentos narrados neste texto. Depois de ter, em meados dos anos 1990, exposto a relevância do território na constituição da cidadania moderna tal como ela se exprimiu no Ocidente desde a Antiguidade (Gomes, 1997), Paulo Cesar Gomes constitui o Grupo de Pesquisa Território e Cidadania, do qual ainda é coordenador. Ele privilegiou, de início, um olhar sobre as disputas pelos espaços de exercício da cidadania, isto é, uma análise territorial da cidadania e democracia modernas. Poucos anos depois, já no início dos anos 2000, suas publicações sinalizam a ambiguidade entre os limites do conceito de território e a variedade de formas e comportamentos que constituem os espaços de exercício da cidadania -os espaços públicos-. Ao mesmo tempo, formou-se, tanto pelo interesse pessoal do coordenador quanto pelo dos demais integrantes do Grupo de Pesquisa, a

10 Essa propriedade dos espaços públicos, que consiste na capacidade de "gerar uma infinita e recíproca cadeia de observadores" (Gomes e Parente-Ribeiro, 2013:31), é denominada de "reflexividade" (Gomes, 2012; Gomes e Parente-Ribeiro, 2013). 
0 espaço, o drama: vida pública e... RAFAEL Augusto ANDRADE Gomes

rotina de discussões sobre a investigação das imagens a partir de um ponto de vista geográfico, particularmente as imagens de espaços públicos, o que culminou na proposição do conceito de cenário em meados dos anos 2000.

Entre 2007 e 2009, como relembra Gomes (2011a:15), dois projetos de investigação foram submetidos e aprovados por agências de fomento à pesquisa: um sobre o "potencial político desses espaços [os públicos] e de suas imagens nas sociedades contemporâneas"; outro que envolvia a produção de imagens dos espaços públicos do Rio de Janeiro e o debate sobre sua relevância na cidade. É nesse quadro que se desenvolveu, no interior do Grupo de Pesquisa Território e Cidadania, uma série de esforços para a produção de um filme sobre importantes espaços públicos do Rio de Janeiro: Lapa, Largo do Machado, as praias da Zona Sul da cidade, entre outros diversos logradouros (Gomes, 2011a, 2011b). Um dos principais animadores das iniciativas do grupo, até então, era o próprio Paulo Cesar Gomes, mas, no mesmo período, a geógrafa Leticia Parente Ribeiro se juntou a ele na coordenação das atividades de pesquisa.

O modelo adotado para a gravação das cenas dos espaços públicos remete à principal diferença entre a cena pública e a cena no teatro ou no cinema, discutida anteriormente na apresentação do conceito de cenário (Gomes, 2008a): "deveríamos partir para a gravação com algumas ideias na cabeça, mas deixaríamos também que a câmera capturasse livremente o movimento das ruas" (Gomes, 2011a:17). Nessa perspectiva, a produção de imagens por geógrafos, para ser fecunda à pesquisa, não precisa se confundir com as imagens produzidas por profissionais de outras competências. Mudam-se os profissionais, mudam-se as competências e, frequentemente, os objetivos da produção de imagens. Enquanto, para alguns, o controle da composição e do conteúdo da cena é fundamental, para outros, é exatamente a imprevisibilidade das ações e das composições que mais interessa.

Na condição de geógrafos, preocuparam-se mais com a escolha dos lugares de gravação, dos pontos de vista, dos enquadramentos, entre outras condições geográficas do olhar (Gomes, 2013), do que propriamente com o controle absoluto da narrativa e do roteiro. Em 2009, com o título Cenas sinais: as sinalizações dos espaços públicos, é concluída a primeira sequência fílmica a partir da edição do material bruto. Nesta sequência, as situações apresentadas nas cenas indicam a variedade de "sinalizações e indicativos que regulam nossos comportamentos" e que, "ao serem mostrados em uma tela, ao serem isolados do fluxo de informação, conseguimos, finalmente, percebê-los como orientações" (Gomes, 2011a:18). Ressalte-se, mais uma vez, que não havia um roteiro para demonstrar a regulação dos comportamentos pelos sinais (placas, faixas de travessia de pedestres) dispostos nas superfícies dos espaços públicos.

Decerto, isso não quer dizer que os conhecimentos de outros profissionais, como os estudiosos do cinema e da comunicação, tenham sido desconsiderados; antes pelo contrário, a produção do filme pavimentou colaborações futuras entre o Grupo de Pesquisa Território e Cidadania e especialistas da Escola de Comunicação da UFRJ. Em 2010, inclusive, outras sequências fílmicas foram produzidas a partir dessa colaboração e reunidas no filme Cenas da vida urbana: Espaços públicos e Cidadania (2012). Esse filme foi produzido em resposta a um edital do Ministério da Educação, através da Secretaria de Educação Superior, e tinha o objetivo de atender a demanda por materiais pedagógicos, no Ensino Médio, que contemplassem eixos dos parâmetros curriculares 
0 espaço, o drama: vida pública e... RAFAEL AUgusto ANDRADE GoMES

vinculados ao reconhecimento do significado dos espaços de vivência cotidiana e exercício da cidadania (Ministério da Educação, 2006). Além do filme, composto de cinco partes, os docentes das escolas da rede pública receberam uma cartilha com temas, questões e sugestões de atividades.

Os integrantes do Grupo de Pesquisa Território e Cidadania ainda utilizam metodologias visuais em suas pesquisas e, em mais de uma ocasião, entre os anos 2010 e 2013, foram convidados a ministrar oficinas de imagens para estudantes de graduação e pós-graduação em geografia noutras cidades brasileiras -Recife, Natal, Florianópolis, Campinas e Curitiba-. "De onde podemos olhar a cidade? Para onde devemos olhar para vê-la e reconhecê-la? Que imagens urbanas podem bem representá-la? Como os significados circulam através das composições e do sequenciamento de imagens tomadas da cidade?", questionam Gomes e Parente-Ribeiro (2012), coordenadores das oficinas de imagens, enquanto apresentam a proposta metodológica. Em um primeiro momento, a oficina tinha o objetivo de difundir e desenvolver o uso de "ferramentas para a análise de imagens em geografia"; mas, num segundo momento, constituiu-se como uma oportunidade de "recolher informações sobre como esse processo de produção de imagens está relacionado a um imaginário espacial de uma dada cidade" (Gomes e Parente-Ribeiro, 2012:63-64).

As oficinas eram organizadas em duas partes: um módulo de fotografia, com a tomada de imagens fixas da cidade, e um módulo audiovisual, no qual os participantes produziam planos-sequência ou fotos-sequência com as imagens do módulo anterior. Em ambos os exercícios, a partir da análise das imagens fixas sequenciadas ou de pequenas gravações de áreas das cidades, foi possível "identificar um repertório comum de formas, cores e significados" (Gomes e Parente-Ribeiro, 2012:67). Quais os elementos da morfologia urbana aparecem em destaque nos planos-sequência e nas fotos-sequência? Quais ações, comportamentos e significados estão associados a essas formas urbanas? As imagens produzidas, qualquer que seja a cidade, não tinham o objetivo de demonstrar ou exemplificar uma determinada conclusão unívoca, mas consistiam em um "meio de observação e de debate", um "meio de construir questões" (Gomes e Parente-Ribeiro, 2013:33).

Como vimos, em contraste com os filmes roteirizados, a cena pública, esse fluxo sequenciado de imagens em movimento que apresenta a vida dos espaços públicos, não é composta por gestos, comportamentos, figurinos e ritmos orquestrados. Para fugir às armadilhas teleológicas da roteirização, uma das estratégias, talvez a mais comum quando se trabalha geograficamente com as imagens, é a multiplicação dos pontos vista, dos ângulos e dos enquadramentos na produção das imagens (Claval, 2012; Gomes, 2013; Gomes e Parente-Ribeiro, 2013). Ainda que apresentada em cenas fragmentadas, parciais e imprevisíveis, a vida pública se constitui, necessariamente, a partir da associação entre o lugar da ação e as ações propriamente ditas -que, por sua vez, são sempre relacionais, pois se apresentam ao olhar do público-. Portanto, as mesmas ações, ou interações sociais, podem ganhar significados distintos de acordo com o lugar no qual se apresentam.

Em outras palavras, as interações sociais que animam os espaços públicos têm uma geografia, e, entre 2013 e 2015, os integrantes do Grupo de Pesquisa Território e Cidadania desenvolveram o projeto que resultaria na publicação do livro Formas de la Sociabilidad 
0 espaço, o drama: vida pública e...

(Gomes e Parente-Ribeiro, 2019). Cabe, antes de repassar o conteúdo do livro, um esclarecimento sobre o conceito de sociabilidade. Malgrado as divergências que essa definição possa causar, Gomes e Parente-Ribeiro (2019) consideram a sociabilidade como apenas um dos diversos tipos possíveis de interação social, à maneira como definiu o sociólogo Simmel (2006:64): "um exercício livre de todos os conteúdos materiais". Essa definição pressupõe considerar, necessariamente, a existência de uma forma de interação entre indivíduos despida de quaisquer interesses e finalidades definidas $a$ priori, tais como "instintos eróticos, impulsos religiosos, objetivos de defesa" (Simmel, 2006:60), dentre outras tantas metas que impulsionam um indivíduo a interagir com os demais. A sociabilidade, portanto, é uma forma de interação cujo objetivo primordial do indivíduo é a própria interação, pôr-se em contato e encontrar outros indivíduos.

É evidente que o Rio de Janeiro, como qualquer outra cidade, possui uma imensa variedade de lugares de sociabilidade, isto é, pontos que polarizam as situações de encontro social das pessoas. Do mesmo modo que nas pesquisas anteriores do Grupo Território e Cidadania, nos artigos do livro Formas de la Sociabilidad (Gomes e Parente-Ribeiro, 2019), o olhar dos pesquisadores não se dirigiu a qualquer tipo de lugar de sociabilidade, mas a um tipo específico de lugar, os públicos: "Nossa atenção está dirigida a esses 'lugares' onde o evento principal, o interesse que mobiliza, é o encontro social, ou seja, um grupo variado e heterogêneo de pessoas é direcionada para um 'lugar' público com o objetivo final de encontrar outras pessoas" (Gomes e Parente-Ribeiro, 2019:27). Qual é a geografia das situações públicas de sociabilidade da cidade do Rio de Janeiro?

\section{Ato 4: 0 livro como a síntese de múltiplas trajetórias}

Os textos compilados no livro Formas de la Sociabilidad, cuja primeira edição veio a lume no final de 2019, ampliam a extensa lista de publicações geográficas dedicadas à investigação da cidade, especialmente do Rio de Janeiro, desde a institucionalização da disciplina nas universidades brasileiras, em meados dos anos 1930 ${ }^{11}$ Composto por mais de dez textos, o Formas de la Sociabilidad está fundamentado em conceitos variados, entre os quais se destacam o de sociabilidade, que ocupa toda a obra por ser o tipo de interação social investigada, e o de espaço público, que é igualmente relevante por qualificar o estatuto dos espaços nos quais tal tipo de interação se conforma. Atentemo-nos aqui ao uso do vocábulo forma acompanhado do radical latino con, pois a ele e a alguns de seus congêneres dedicaremos alguns breves comentários nas linhas subsequentes.

Forma, fisionomia, aparência, aspecto, feição e tantas outras expressões cognatas, pelo menos desde o início do século XX, fizeram parte do vocabulário dos geógrafos para a descrição das cidades. Não é incomum, portanto, ao folhearmos textos geográficos dos últimos 100 anos, que nos deparemos com essas palavras -empregadas individualmente ou de maneira combinada-. Cada um desses termos, ainda que recorrentes em passagens de diversos estudos geográficos, possui uma história particular, ainda a ser escrita, na qual o conteúdo semântico da palavra se associa a diversas práticas e ideais de pesquisa. Mesmo o conceito de forma que, segundo a definição axiomática de Frolov (1975:676), corresponde ao arranjo dos elementos que compõem um corpo

11 Para citar apenas alguns poucos exemplos de pesquisas originais sobre a cidade do Rio de Janeiro, sugere-se a consulta de Geiger (1960), Pinto (1965), Segadas Soares (1965), Castro (1965) e Abreu (1987, 2010). 
0 espaço, o drama: vida pública e...

ou a superfície que o circunda, reúne uma grande variedade de camadas de significado acumuladas ao longo do tempo. A análise de diversos índices de medição das formas, empreendida por Frolov (1975), torna evidente a variedade de parâmetros utilizados para a classificação morfológica dos fenômenos geográficos.

O estudo da forma é, segundo nos parece, fundamental para a ciência geográfica na descrição dos fenômenos. Tomemos como exemplo a terminologia geomorfológica. A lista de termos para designar determinadas feições do modelado terrestre é muito longa, varia ao sabor de princípios teóricos, procedimentos metodológicos, escalas de análise, parâmetros morfológicos e morfométricos, entre outras circunstâncias, como a seguinte amostra desordenada e nada exaustiva indica: cânion, terraço, depressão, chapada, pediplano, peneplano, colina, pico, falésia, istmo, cabo, península, pontal, baía e assim por diante. Observa-se, é claro, que muitas nuances diferenciam esses termos uns dos outros e não convém aos nossos propósitos neste texto distingui-los. Embora tenha sido utilizada como um critério para a descrição de feições geomorfológicas, paralelamente, a forma também tem sido útil à caracterização de áreas urbanas, comerciais e políticas (Boyce e Clark, 1964).

A despeito das diferenças entre os estudos de língua portuguesa, francesa e inglesa, sobretudo estadunidense e britânica, entre os anos 1920 e 1960, notamos a relevância da dimensão morfológica na geografia urbana. Davies (1933), por exemplo, parte da análise da formação de quatro cidades polacas -Posnânia, Danzigue (atual Gdańsk), Cracóvia e Varsóvia- e, desse conjunto, desenvolve o argumento de que "o plano da cidade pode ser considerado em alguns aspectos como uma imagem das relações humanas no espaço e no tempo" (Davies, 1993:25, tradução livre). O plano urbano deixaria entrever, através das características morfológicas de suas partes, as variações históricas da relação entre condições geográficas, atividades e necessidades humanas (Fleure, 1920; Davies, 1933; Dickinson, 1934). No ano seguinte à publicação de Davies (1933), com base no pressuposto de que a morfologia urbana consiste na descrição e interpretação dos assentamentos urbanos, Dickinson (1934) apresenta uma classificação morfológica dos planos urbanos da Ânglia Oriental (East Anglia), reino inglês no período medieval, em três grandes grupos: regulares, irregulares e lineares.

A maneira como Dickinson (1934) desenvolve a análise e, posteriormente, a classificação morfológica dos planos urbanos da Ânglia Oriental é uma orientação para que o pesquisador, ao fazê-lo em outras áreas de estudo, não se limite a considerar apenas a visão bidimensional ou vertical da forma da cidade -observação corroborada quatro décadas depois por Frolov (1975)-. Cabe ao estudioso da morfologia urbana, segundo Dickinson (1934:37, tradução livre), preocupar-se "com o padrão (layout das ruas) e formas da cidade como um todo". O plano da cidade, portanto, é preenchido por volumes. Para Claval (2012), essa passagem, ou trânsito, entre modos de ver a paisagem é o que caracteriza o olhar geográfico. De um lado, a observação horizontal, que abarca o olhar do caminhante. De outro, a visão vertical, geralmente na forma de um mapa, "que permite as generalizações, evidencia a estrutura das distribuições e permite a leitura dos agrupamentos regionais", mas, às vezes, leva-nos "a esquecer os objetos que realmente importam na vida das pessoas” (Claval, 2012:251).

O caso britânico, ilustrado pelos trabalhos de Fleure (1920), Davies (1933) e Dickinson (1934), não é nada excepcional entre os estudos morfológicos da geografia urbana na 
0 espaço, o drama: vida pública e...

primeira metade do século XX. Sabe-se também que alguns geógrafos franceses, particularmente aqueles que se dedicaram, parcial ou integralmente, ao estudo das cidades, exercitaram a observação horizontal e vertical da morfologia urbana. Jean Brunhes, por exemplo, em capítulo de seu La Géographie Humaine (1925:99-282) dedicado aos "fatos da ocupação improdutiva do solo: casas e caminhos", inicia a análise da fisionomia da instalação humana a partir da unidade de habitação, a casa, em direção à distribuição (dispersa ou aglomerada) dos conjuntos de tipos de habitação. Parecenos, com isso, que, por mais impactante e celebrada que tenha sido a visão de avião na observação geográfica, da qual Jean Brunhes foi um notório entusiasta (Besse, 2014), a multiplicação dos pontos de vista na descrição da paisagem não deixou de ser um dos traços distintivos do olhar geográfico (Claval, 2012; Gomes, 2013).

Um pesquisador de planejamento e design urbanos da Universidade de Hong Kong, Alain Chiaradia (2019), afirma que os estudos de morfologia urbana, desde pelos menos meados do século XX, com as obras de William Foote Whyte (1914-2000), Kevin Lynch (1918-1984) e Jan Gehl (1936-presente), estão direcionados à busca de conexões entre a forma urbana e as atividades humanas. De fato, as contribuições de Whyte, Lynch e Gehl estão presentes, direta ou indiretamente, na sustentação teórico-metodológica do Formas de la Sociabilidad (Gomes e Parente-Ribeiro, 2019). No entanto, ao que parece, mais do que simplesmente a adoção de teorias da forma urbana desenvolvidas por arquitetos, urbanistas e sociólogos, os autores basearam-se em modos de ver e descrever a morfologia das cidades com longa história na ciência geográfica.

Tudo o que foi dito acima pode ser constatado no texto de abertura da primeira parte do Formas de la Sociabilidad, intitulado De olho na areia: variações morfológicas sobre a regularidade das superficies arenosas. "Como as qualidades físicas de um lugar intervêm nos tipos e conteúdos das relações entre as pessoas?”, questionam os autores. De forma muito significativa, as imagens utilizadas por Nikolas Zanette e Paulo Cesar Gomes, autores desse texto, expressam a combinação entre pelo menos duas formas de ver o fenômeno da ocupação da faixa de areia das praias do Rio de Janeiro, as visões vertical e horizontal. Uma das imagens utilizadas pelos autores, com uma visão vertical ou zenital de um mapa, apesar de reforçar a homogeneidade do revestimento da faixa de areia, apresenta a variedade na distribuição de pessoas, equipamentos e atividades de um ponto na calçada da orla da praia até a porção da areia adjacente ao mar. Com a observação horizontal, ou seja, no ângulo dos frequentadores, é possível identificar os volumes, a densidade das ocupações das pessoas e a disposição dos objetos na superfície arenosa.

A despeito da morfologia e revestimento regulares, as praias, dentre os diversos espaços públicos da cidade do Rio de Janeiro, estão entre os espaços com maior densidade de regulação e normatização sobre os tipos de uso e comportamentos admitidos no interior de seus limites. Um dos principais indicadores desse fato é a variedade de agentes públicos, sobretudo fiscalizadores, que estão presentes nas praias da cidade para controlar a aplicação das normas e dirimir possíveis conflitos de convivência entre grupos ou indivíduos. Todavia, a regulação dos comportamentos nas praias do Rio de Janeiro não se efetua exclusivamente a partir da coerção dos agentes públicos. A classificação espacial é, frequentemente, responsável por atenuar as tensões sociais que se apresentam nos espaços públicos. Como observa Gomes (2020:163), "a qualificação espacial, que funciona como um guia para delimitar comportamentos, é um dos mais eficientes instrumentos para o estabelecimento de uma convivência social consciente da diversidade de interesses". 
0 espaço, o drama: vida pública e...

As superfícies arenosas nos espaços públicos do Rio de Janeiro, no entanto, não se resumem às praias. Ao contrário, diversas praças e parques da cidade recriam, a partir da combinação de faixas de areia com áreas úmidas -como lagos e chafarizes-, o universo de símbolos e valores associados à praia no imaginário espacial sobre o Rio de Janeiro. Os parques urbanos do Rio de Janeiro -em especial três deles: a Quinta da Boa Vista, o Parque do Flamengo e o Parque de Madureira- foram objetos do escrutínio de Paula Trojan no segundo capítulo do Formas de la Sociabilidad (Gomes e Parente-Ribeiro, 2019). Com ênfase nas superfícies revestidas por gramados, a autora apresenta um quadro da associação entre a morfologia do parque e as formas de uso e ocupação, com base em um conjunto de variáveis: extensão dos parques; proporção de áreas gramadas; tipos de atividades realizadas; lugares de concentração de pessoas; itinerários e trajetórias dos usuários no parque.

O aspecto morfológico é, segundo a análise de Paula Trojan, a expressão de três modelos paisagísticos da civilização ocidental. O mais antigo dos três parques, a Quinta da Boa Vista, cuja origem remonta ao século XIX, foi organizado como um espaço de admiração da natureza, uma ruptura na malha urbana; por esse motivo, os equipamentos e o desenho do parque privilegiam o lento deslocamento e a contemplação. O Parque do Flamengo, por sua vez, é fruto do urbanismo modernista em meados do século XX, e sua organização interna, em comparação com a da Quinta Boa Vista, privilegia a funcionalidade e o direcionamento das atividades dos usuários. Há, ainda, o Parque de Madureira, inaugurado em 2012. Em contraste com os anteriores, este parque não possui tantas áreas revestidas por gramados e a maioria de suas superfícies, tais como as quadras esportivas, é destinada ao desempenho de atividades específicas.

Paula Trojan argumenta que, para captar o papel da morfologia na orientação dos usos e apropriações dos parques, é preciso examinar os modelos paisagísticos e seu papel nas formas de organização do ócio e do lazer dos cidadãos. Estejamos ou não de acordo com tal pressuposto, a hipótese proposta pela autora é tributária de uma longa tradição nos estudos geográficos: a paisagem concebida como "obra" ou "espelho da civilização" (Brunhes, 1925; Monbeig, 1940). Jean-Marc Besse (2014:12), a propósito das "cinco problemáticas paisagísticas que coexistem no pensamento contemporâneo”, afirma que essa tradição concebe a paisagem como um "território produzido pelas sociedades na sua história”. Se, aqui, optamos por citar os trabalhos de Jean Brunhes (1925) e Pierre Monbeig (1940), Besse (2014) escolhe ressaltar também as contribuições de Pierre Deffontaines (1894-1978) e John B. Jackson (1909-1996).

Quaisquer sejam os autores citados, importa-nos destacar, dessa compreensão da paisagem como obra, que a morfologia é a "expressão de uma relação mais profunda, -vertical-, entre o homem e a superfície da Terra, uma relação ativa e prática pela qual o homem transforma o meio natural" (Besse, 2014:33). Em outras palavras, a paisagem é a manifestação física de um espaço organizado para atender aos valores e necessidades humanos; entre os principais valores humanos relativos à obra paisagística, completa Besse (2014), estão a "boa convivência" e o "bem-estar" das comunidades humanas. Os espaços públicos são, como dissemos ao longo de todo este texto, terrenos privilegiados de inscrição e reconhecimento das tensões geradas pelo convívio de indivíduos com interesses diferentes. Então, como os espaços públicos são organizados para a "boa convivência" humana? 
A questão pode ser respondida se retomarmos a discussão anterior sobre o espaço público como lócus da lei democrática. $\mathrm{O}$ acesso indiscriminado dos indivíduos aos espaços públicos, por exemplo, ilustra a relação contratual da qual esse tipo de espaço é derivado; "esse contrato cidadão corresponde, então, a um pacto que é ele mesmo, simultaneamente, relação de pertencimento a uma comunidade política e a um território" (Gomes, 2012:30). Isso quer dizer que, em meio à pluralidade de interesses em conflito, ao Estado-nação, forma territorial das comunidades políticas modernas, caberá o estabelecimento dos parâmetros de uso e ocupação dos espaços públicos. Esses parâmetros devem, assim como quaisquer outros que visem à regulação das sociedades democráticas, estar em acordo com os princípios de isonomia dos cidadãos, respeito às liberdades individuais e bom convívio social.

Se, à primeira vista, nos dois capítulos iniciais do Formas de la Sociabilidad, a relevância das obras de Georg Simmel (1858-1918) e Erving Goffman (1922-1982) para a interpretação da geografia das interações sociais nos espaços públicos não é evidente, a impressão muda completamente do terceiro capítulo em diante. É, por exemplo, o caso do texto escrito por Washington da Silva e Sue Coccaro sobre os terrenos e superfícies dedicados aos jogos nos mesmos três parques urbanos citados acima (Quinta da Boa Vista, Parque do Flamengo e Parque de Madureira). Como ressaltam os autores, os locais comuns para a realização de jogos, partidas e outras atividades lúdicas são aqueles preconcebidos para tal, a exemplo de quadras poliesportivas, pistas de skate e mesas de xadrez. A prática de atividades lúdicas, porém, é admitida em porções do espaço público que não foram planejadas ou delimitadas para abrigá-las. Outra situação possível -e, aliás, bastante comum nas grandes cidades- é a reconfiguração temporária de superfícies, como os gramados dos parques, para a execução das atividades lúdicas. É óbvio que essa mudança de lugar da atividade lúdica pode acarretar uma série de conflitos com outros usos, práticas e comportamentos nos espaços públicos.

Washington da Silva e Sue Coccaro afirmam, inspirados na sociologia interacionista, que "os jogos parecem reproduzir de maneira simples as estruturas de situações da vida real” (Goffman, 2016:27). As ocasiões de interação social nos espaços públicos, ou seja, quando "as pessoas se encontram na presença imediata umas das outras" (Goffman, 2016:14), possuem as mesmas duas características essenciais à execução das atividades lúdicas: conjunto de regras compartilhado pelos participantes e formas físicas que guiam as ações de acordo com a estrutura das regras. Um jogo de futebol bastará como exemplo para ilustrar a constatação dos autores. Assim como o terreno dos demais jogos, o campo de futebol se caracteriza, sobretudo, pela existência de determinadas linhas ou limites que contêm as ações em seu interior. Essas linhas, ou códigos simbólicos, são compartilhadas pelos indivíduos que participam do jogo. Aqueles que estão do lado de fora do campo, os espectadores, não têm lugar dentro do campo de futebol enquanto o jogo está acontecendo. Bastaria a transgressão de tal regra para que a interação entre jogador e espectador, até então estável, se tornasse conflitiva.

Além das superfícies arenosas ou gramadas dos parques e praias, existem outros espaços que concentram a vida pública do Rio de Janeiro e, por conseguinte, estão presentes no imaginário associado à identidade carioca. O caso do Calçadão de Copacabana é um inequívoco exemplo disso e, em conjunto com outras calçadas da cidade do Rio de Janeiro, foi objeto de discussão no quarto capítulo do Formas de la Sociabilidad, escrito por Karina Fioravante e Igor Robaina. Qual é o papel das calçadas na vida 
pública, afinal? É a essa pergunta, cuja aparência simples pode enganar, que os autores pretendem responder. Um breve resumo da evolução das calçadas na história, sobretudo de países europeus, convence-nos de que essas superfícies são espaços de encontro entre diversas práticas sociais e interação entre os cidadãos. De fato, vê-se que o desenho e a regulação das calçadas, ao menos na legislação municipal do Rio de Janeiro e nos planos urbanos, priorizam o deslocamento e a circulação dos pedestres -e, eventualmente, de ciclistas-.

Seria preciso uma minuciosa pesquisa da história das calçadas para determinar as etapas da evolução, seguramente variável de um lugar a outro, que nos conduziu à condição atual, na qual o design, a regulação e o ordenamento das calçadas são guiados por sua função na circulação urbana. Não esqueçamos, porém, que uma infinidade de autores ao longo do século XX, tais como Whyte (1943), Jacobs (1961) e Gehl (1987), ressaltou a variedade de atividades que ocorrem nas calçadas e seu papel no fomento às interações sociais públicas. As calçadas, portanto, são animadas por formas de ocupação diversas, que extrapolam em demasia a pura funcionalidade do deslocamento individual. Everardo Backheuser (1944:3), em um estudo descritivo do comércio ambulante nas ruas do Rio de Janeiro, utiliza a expressão "ocupações de rua" para designar as atividades econômicas e não-econômicas que imprimem vivacidade ao panorama urbano.

Ocupações, inclusive, é o título da segunda parte do Formas de la Sociabilidad. Com autoria de André de Souza e Igor Campos, o primeiro capítulo dessa parte nos fornece uma valiosa ilustração das possibilidades metodológicas de investigação geográfica da sociabilidade pública. Para os autores, as interações sociais em espaços públicos e, em especial, a sociabilidade pública, constituem a base da vida pública das sociedades democráticas contemporâneas. Como já dissemos acima, a partir da simples observação, é possível notar que os espaços públicos não são homogêneos; alguns deles, em contraste com diversos outros na malha urbana de uma cidade, são mais densos de significados e concentram uma variedade enorme de públicos, práticas e comportamentos. De forma um tanto curiosa, alguns espaços públicos são capazes de atrair mais pessoas. A esses lugares, os autores denominam "lugares centrais de sociabilidade". A denominação é inspirada, claro, na já conhecida "Teoria dos Lugares Centrais" (Christaller, 1966).

A tese de André de Souza e Igor Campos, então, é de que, assim como na proposta de Christaller (1996), a centralidade de um espaço consiste numa razão entre a oferta de bens e serviços, o tamanho das áreas polarizadoras e a distância entre uma área e outra. No caso dos lugares centrais de sociabilidade, isso quer dizer, em suma, que, quanto maior a capacidade de um espaço público em atrair pessoas e mais heterogêneo o público frequentador, tão maior será sua centralidade no sistema de espaços públicos de uma cidade. Para ilustrar essa tese e aprofundar a analogia com o modelo de Christaller (1966), os autores investigam situações de sociabilidade noturna em dois lugares da cidade: a Lapa, um bairro próximo ao centro, e a Praça São Salvador, um pequeno logradouro no bairro Laranjeiras, Zona Sul do Rio de Janeiro. Ambos são lugares centrais de sociabilidade, isto é, polarizam fluxos de pessoas que se reúnem sem qualquer interesse ou finalidade, senão a do próprio prazer propiciado pelo encontro social.

Citamos, poucas linhas acima, uma nova expressão: sociabilidade noturna. Essa menção não foi acidental. Os espaços públicos têm frequentemente sido investigados, seja por geógrafos ou outros especialistas, sem que os períodos do dia ou as condições 
de luminosidade estejam entre as variáveis de análise. O segundo texto de Igor Robaina, autor cujo trabalho já foi citado, em coautoria com Amanda de Carvalho, aprofunda a hipótese de que as condições de luminosidade participam do espetáculo da sociabilidade nos espaços públicos do Rio de Janeiro. Os autores exploram tal hipótese a partir de três exercícios de observação dos cenários de interação pública em parques e praças das Zonas Sul e Norte da cidade. O primeiro, denominado "ilhas de sociabilidade", descreve áreas nas quais as sombras causadas pela incidência solar sobre trechos arborizados delimitam pequenos núcleos de interação social.

O segundo exercício descreve um evento regular, uma espécie de "encontro marcado", no qual as pessoas cessam as atividades corriqueiras e se deslocam a um ponto da praia para observar e, até mesmo, aplaudir o pôr-do-sol. O último exercício, realizado em uma praça do bairro Tijuca, consiste na descrição da variedade de comportamentos associados aos jogos de luz e sombra ao longo de um mesmo dia. No caso descrito por Robaina e Carvalho, em contraste com parte da literatura científica, alguns comportamentos transgressores -uso de entorpecentes, por exemplo- são expostos e apresentados em áreas mais iluminadas do que todas as ruas do entorno da praça. Mesmo cenas como essas, a despeito da ilegalidade ou fuga às normas, quando apresentadas na penumbra de uma praça, garantem a expressão pública dos comportamentos.

Noite, sombra, comportamentos desviantes e "sensação de perigo", essas associações reaparecem no capítulo seguinte do Formas de la Sociabilidad, cuja autoria é dividida entre Karina Fioravante, Hernando Sanchez e, novamente, Igor Robaina. Os autores, apoiados em estudos sobre percepção ambiental e, sobretudo, nos conceitos de topofilia e topofobia (Tuan, 1974, 1979), argumentam que a aversão e o apreço por determinados lugares são produtos da forma como as pessoas os vivenciam e imaginam. A partir de entrevistas e questionários com os usuários dos três maiores parques do Rio de Janeiro, os autores identificaram, em consonância com Tuan (1974; 1979), que as expressões topofilicas e topofóbicas se associam a três variáveis: atividades realizadas no lugar; as práticas de interação social; as condições físicas do ambiente. Em outras palavras, a percepção "simpática" ou "antipática" das pessoas em relação a um lugar está vinculada às características materiais, aos comportamentos individuais e à expectativa das interações sociais que se realizarão nesse lugar.

Para encerrar a segunda parte do Formas de la Sociabilidad, resta-me discutir apenas o texto Escutar a cidade: som e sociabilidade, escrito por Renato Frias e Ana Machado. Em mais de uma ocasião, tentamos deixar claro ao leitor que a cena pública é concebida, mutatis mutandis, como a cena de uma apresentação teatral ou projeção cinematográfica. Para além das variações, todas as cenas são organizadas segundo determinadas variáveis. A primeira é que, para existir, a ação encenada depende de um espaço físico, um palco ou superfície na qual os objetos estão organizados uns em relação aos outros. O segundo ponto está relacionado à existência de regras, normas e acordos que guiam os comportamentos e as ações apresentados. O terceiro ponto associa-se à ideia de que, em uma cena, as ações não são absolutas, mas sim realizadas de acordo com as qualidades do lugar no qual ocorrem -luminosidade, equipamentos, entre outras características-.

Vê-se, certamente, que o texto de Renato Frias e Ana Machado integra mais uma variável à analogia teatral e cinematográfica da cena: composição sonora. De fato, desde a proposta do conceito de cenário (Gomes, 2008a:191), a investigação geográfica dos espaços 
0 espaço, o drama: vida pública e...

públicos no Grupo de Pesquisa Território e Cidadania tem sido orientada, sobretudo, pela compreensão de que as "imagens são produtos quase exclusivamente visuais"; tal afirmação foi corroborada por diversos outros autores ao longo dos anos (Alpers, 1983; Jenks, 1996; Latour, 2015). Conscientes da proeminência da imagem na cultura ocidental, de forma geral, e no exame dos espaços públicos, em particular, Frias e Machado propõem uma reflexão sobre o significado dos sons, mais especificamente da música, na organização das interações sociais nos espaços públicos da cidade do Rio de Janeiro. Segundo os autores, a partir da análise de formas de ocupação do espaço público associadas à música, como é o caso da roda de samba, as interações sociais estão associadas a composições sonoras específicas, "que definem limites especiais e, por consequência, influem diretamente na distribuição das pessoas nos espaços públicos" (Frias y Machado, 2019:s/p).

A penúltima parte do Formas de la Sociabilidad, intitulada Descontinuidades, é composta por três capítulos. O primeiro deles, escrito por Ana Machado e Thomaz Menezes Leite, retoma a ideia, já discutida aqui, da classificação ou qualificação espacial como instrumento de controle das interações e do convívio social (Gomes, 2020). De uma maneira geral, os espaços públicos, se concebidos como cenários da vida comum nas cidades, não são planícies indiferenciadas. Pelo contrário, eles expressam e são constituídos por descontinuidades e limites. Compreender o significado de tais descontinuidades, por exemplo, de um muro ou alambrado, requer que consideremos o ambíguo significado dos limites. De um lado, os limites possibilitam a diferenciação, classificação e separação dos tipos de uso e dos comportamentos nos espaços públicos. Por outro lado, eles também podem funcionar como uma interface entre os espaços que distinguem, ou seja, os limites agem como reguladores de usos, ritmos e acessos.

No segundo capítulo sobre as "descontinuidades", em contraste com os demais textos do Formas de la Sociabilidad, as autoras, Mirelle Alfano e Sue Coccaro, não apresentam uma reflexão pautada especificamente na observação de espaços públicos do Rio de Janeiro. A questão tratada é geral: quais são as consequências da vida virtual (online) para a sociabilidade pública? Do ponto de vista da discussão realizada até aqui sobre os espaços públicos e a sociabilidade, duas respostas são especialmente importantes na argumentação de Alfano e Coccaro. Em primeiro lugar, as interações virtuais e físicas não podem ser vistas, ao menos de forma absoluta, como uma oposição entre disponibilidade e indisponibilidade para o contato social. Isso quer dizer, por exemplo, que, apesar do uso de um dispositivo com acesso à internet em público comunicar a indisposição ao contato social, há uma série de aplicativos online que fomentam o encontro e a reunião pública entre desconhecidos. Em segundo lugar, a transmissão de informação simultânea sobre os lugares atualiza a concepção de copresença, que é um dos princípios fundadores do conceito de espaço público (Gomes, 2012). Ao se conectar virtualmente e compartilhar suas cartografias pessoais, os indivíduos ampliam a visibilidade e conexão de outras pessoas com os lugares nos quais elas se encontram. Mais que simplesmente descontinuidades, há situações nas quais a sociabilidade virtual e a sociabilidade presencial se complementam.

A última "descontinuidade" tratada no Formas de la Sociabilidad é aquela entre o dia e a noite urbanas, tópico examinado por Marcos Góis e Renan França. O geógrafo Marcos Góis, que iniciou sua participação no Grupo de Pesquisa Território e Cidadania em 2006 e, atualmente, divide a coordenação com Paulo Cesar Gomes e Leticia Parente 
Ribeiro, possui uma larga experiência na investigação das paisagens e cenários noturnos do Rio de Janeiro (por exemplo, ver Góis, 2017). O estudo geográfico das interações sociais noturnas serve aqui, então, como uma oportunidade para repensar o exercício da vida pública num quadro de referência distinto daquele predominante no imaginário social -no qual a noite é o momento do descanso privado e das atividades transgressoras-. Os autores apresentam, com efeito, que a introdução da iluminação artificial amplia o leque e redefine a organização espacial dos comportamentos noturnos. Sob essa ótica redefinida da noite, a sociabilidade pública noturna, antes associada à transgressão, realiza-se a partir de comportamentos não tão distintos daqueles realizados no dia. No entanto, a iluminação artificial não pode ser desconsiderada, pois ela estabelece novos jogos de luz e sombra e, como dissemos, reorganiza aquilo que se apresenta ou se esconde da apreciação pública.

Há, como dissemos, no vocábulo forma, um apelo imediato ao conjunto e arranjo de elementos que compõem um corpo ou a superfície que o delimita (Frolov, 1975). Quando assim entendida, segundo Gomes e Parente-Ribeiro (2019:36) no texto introdutório ao Formas de la Sociabilidad, a forma corresponde a uma "materialidade física, uma figura concreta". A palavra forma, prosseguem os autores, também é utilizada como sinônimo de "modo" ou "maneira" (Gomes e Parente-Ribeiro, 2019:36). Tal como na expressão ponto de vista, que designa, simultaneamente, um lugar de onde se vê algo e "uma maneira de considerar as coisas" (Gomes, 2013:18-19), a forma também carrega a ambiguidade de caracterizar o observador e aquilo que é observado. Em outras palavras, a forma é tanto a configuração material de um ou mais objetos quanto uma maneira de observar tal exterioridade física.

A quarta e última parte do Formas de la Sociabilidad, intitulada Estranhezas, sintetiza explicitamente a ambiguidade da palavra forma através do olhar de três pesquisadores estrangeiros. No primeiro texto, o francês Vincent Berdoulay, que fizera parte da banca de avaliadores da tese de doutoramento de Paulo Cesar Gomes em 1992, e desde meados dos anos 1990 tem colaborado com o Grupo de Pesquisa Território e Cidadania, propõe uma reflexão sobre a resiliência da urbanidade carioca a partir das situações de sociabilidade em espaços públicos. A resiliência, tal como apresentada por Berdoulay, consiste na capacidade de reestruturação de um sistema após situações de estresse e crise. Malgrado os sintomas de regressão do espaço e da vida públicas, entre eles a violência e a existência de vastas áreas controladas por grupos paraestatais (narcotraficantes e milicianos, por exemplo), as ruas, praças e parques do Rio de Janeiro continuam a abrigar interações sociais dos mais diversos tipos.

Essa ambivalência dos espaços públicos -que, a um só tempo, são palco de empatia e aversão, "guerra e paz" (Hiernaux-Nicolás, 2019:11) - ganha forma específica nos textos introdutórios do Formas de la Sociabilidad. O primeiro texto de apresentação do Formas de la Sociabilidad, assinado por Daniel Hiernaux-Nicolás, pesquisador da Universidad Autónoma de Querétaro (México), sintetiza algumas das controvérsias emergentes no debate atual sobre os espaços públicos -debate, inclusive, já indicado pelo autor no próprio título do texto: El espacio público: ¿Guerra y paz?-. Para Hiernaux, ao citar confrontos extraordinários, como aqueles associados aos Coletes Amarelos na França, e ordinários, a exemplo dos cartéis e gangues no México, o espaço público também se constitui como lócus de embates violentos entre indivíduos e grupos. Não há dúvida de que a violência, o medo e a insegurança urbanos figurem entre os principais vetores 
do "esfacelamento dos espaços públicos e recuo da cidadania republicana" (Gomes, 2004:257). No entanto, sem negar a existência da violência, devemos considerá-la como apenas uma das formas de expressão do conflito nos espaços públicos.

Tal como concebido por Simmel (1983:123), o conflito "é um modo de conseguir algum tipo de unidade, ainda que através da aniquilação de umas das partes conflitantes". Em princípio, a sociedade, "para alcançar uma determinada configuração, precisa de quantidades proporcionais de harmonia e desarmonia, de associação e competição, de tendências favoráveis e desfavoráveis" (Simmel, 1983:124). Nem todo conflito, portanto, culmina em violência; antes pelo contrário, como concebidos na sociologia de Simmel (1983), alguns conflitos têm a força de integrar o grupo. Diante de situações conflitivas, os indivíduos realizam uma série de ajustes, negociações e acordos para produzir a coesão da vida pública, que é, necessariamente, compartida com indivíduos diferentes. Para Berdoulay, em seu texto no Formas de la Sociabilidad, se nos espaços públicos testemunhamos a regressão da vida democrática, é também nele que podemos observar os sinais de resiliência e recuperação do sentido público da vida na cidade.

O autor do penúltimo capítulo do Formas de la Sociabilidad, Hernando Cepeda Sanchez, é um historiador que colaborou, entre 2012 e 2014, com o Grupo de Pesquisa Território e Cidadania. Com base em fontes iconográficas, entrevistas, observação participante e descrição etnográfica, Hernando Sanchez apresenta o imaginário e as representações urbanas de um grupo de estrangeiros residentes no Rio de Janeiro. O autor investiga, especificamente, os lugares de residência e de sociabilidade dos membros de um grupo no Facebook cujo principal objetivo é reunir estrangeiros para a realização de práticas esportivas em espaços públicos da cidade. Na seleção dos lugares de residência e sociabilidade, por mais que os estrangeiros se valham de ações e decisões singulares, eles formam redes de sociabilidade que devem ser levadas em consideração para compreendermos como determinados grupos elegem lugares para morar, transitar e interagir socialmente.

O trânsito, a caminhada e a trajetória são temas abordados por Frank Müller, autor do texto que fecha a última parte do Formas de la Sociabilidad. A pergunta que o autor nos faz é a seguinte: quais as consequências da construção do Teleférico da Providência, localizado no morro homônimo, Zona Central da cidade do Rio de Janeiro, na vida urbana dos cidadãos? Para responder a essa questão, Müller nos convida a visualizar, desde pontos de vista distintos, o teleférico. Foi-lhe necessário, para restituir em texto a variedade das ações que ocorrem no interior da cabine do teleférico, lançar mão de uma série de procedimentos tradicionais da ciência geográfica: observação dos comportamentos das pessoas; registro diário das impressões em uma caderneta de campo; fotografias tomadas in situ. Para o autor, o deslocamento no teleférico, ao estabelecer um itinerário entre determinados pontos (estações) na cidade, modifica os ângulos de observação e a experiência urbana dos cidadãos.

Ao cabo deste texto, cumpre afirmar, pela última vez, que os capítulos do Formas de la Sociabilidad (Gomes e Parente-Ribeiro, 2019) pintam cenários dos espaços públicos do Rio de Janeiro. Para além da captura de instantes, ou de imagens fixas, os autores se esforçam para identificar as associações entre o palco, as ações, a iluminação e a composição sonora. Os textos formam, como dissemos, um mosaico, ou, para utilizarmos outra metáfora visual, um álbum de fotografias. Em termos mais genéricos, trata-se da 
0 espaço, o drama: vida pública e... RAFAEL Augusto ANDRADE Gomes

apresentação de um "imaginário espacial”, ou seja, "um álbum de imagens, um atlas de informações geográficas" (Gomes, 2017:141). Ao adentrar nesse universo de imagens sobre espaços públicos do Rio de Janeiro, o leitor, sem o perceber, será convocado a pensar sobre o enredo da vida pública em outros lugares e em outras situações.

\section{Epílogo}

$\mathrm{Na}$ antiga tragédia grega ou nos palcos do teatro elisabetano, o epílogo correspondia ao diálogo ou monólogo final, apresentado após o encerramento da ação dramática de uma trama. Ao longo dos anos, depois de incorporado à narrativa literária, o epílogo também passou a designar, em sinônimo ao posfácio, o texto de fechamento que sucede o conteúdo substantivo de um livro. Mais do que simplesmente o encerramento de um livro ou peça literária, por dirigir-se aos leitores, o epílogo equivale a uma zona de transição entre o texto e o público de uma obra (Genette, 1987). As suas funções, portanto, são diversas: expor o tema, justificar a unidade do livro (no caso de coletâneas), orientar o leitor, entre outras tantas já atribuídas aos prefácios ou prólogos que introduzem os livros.

Reconheçamos, tal como o fez Genette (1987), que, por ser apresentado no final, o posfácio seria pouco eficiente na execução dessas funções. Como guiar ou orientar o leitor depois que a leitura já foi feita? Restaria ao epílogo, portanto, a função corretiva ou, como no teatro, de encerramento da peça apresentada -momento no qual o autor "se despedia do público suplicando-lhe benevolência para os eventuais deslizes do espetáculo" (Moisés, 2004:159). A bibliobiografia -ou, em outros termos, a biografia de um livro- implica reagrupar, na medida do possível, os episódios da vida de uma obra desde a sua concepção até as alterações, críticas e apropriações que a passagem pelo tempo imprime em suas páginas. Cumpre incorporar a essa ideia, ainda, que o biógrafo não pode almejar o esgotamento da história do livro. Não se trata, portanto, de uma narrativa linear e unívoca, de uma busca incessante pela essência do livro, mas de uma história parcial e contada dentro dos limites de determinados critérios, escolhas e parâmetros.

O Formas de la Sociabilidad, "como todos os livros, tem uma história: a história de uma pesquisa que durou muitos anos, a história de uma busca para exprimir os resultados alcançados" (Santos, 2012 [1996]:13). A fim de narrar um ângulo dessa história do livro organizado por Gomes e Parente-Ribeiro (2019), foi-me necessário realizar um excurso temático pela trajetória do Grupo de Pesquisa Território e Cidadania e, sobretudo, do seu mais antigo coordenador. O percurso narrado, no entanto, não tem a pretensão de buscar no passado do grupo de pesquisa a chave para a "leitura correta" ou a melhor compreensão do Formas de la Sociabilidad. Nosso objetivo é bem mais modesto e está refletido no fio condutor da história que contamos: os conceitos geográficos e os exercícios metodológicos. O sentido histórico do livro se deixará entrever, portanto, não pelo simples fato de ele ser um produto da pesquisa, mas também pelo aperfeiçoamento de temas, conceitos e procedimentos desenvolvidos ao longo dos anos. 


\section{O Bibliografía}

»Abreu, M. (1987). A evolução urbana do Rio de Janeiro. Rio de Janeiro: IPLANRIO.

»Abreu, M. (2010). Geografia Histórica do Rio de Janeiro (1502-1700) (Vol. 2). Rio de Janeiro: Andrea Jakobsson, Estúdio e Prefeitura Municipal do Rio de Janeiro.

» Alpers, S. (1983). The Art of Describing. Dutch art in the seventeenth century. Chicago: Chicago University Press.

»Arendt, H. (2007). A condição humana. Tradução de Roberto Raposo (10a ed.). Rio de Janeiro: Forense Universitária.

» Armstrong, P. e Geoffrey, M. (2000). Geographers: Biobibliographical Studies, 1977-2000. Geographical Review, 90(2), 256-259.

» Backheuser, E. (1944). Comércio ambulante e ocupações de rua no Rio de Janeiro. Revista Brasileira de Geografia, 6(1), 3-34.

»Besse, J-M. (2014). O gosto do mundo. Exercícios de paisagem. Rio de Janeiro: EdUERJ.

» Boyce, R. e Clark, W. (1964). The concept of shape in Geography. Geographical Review, 54(4), 561-572.

» Brunhes, J. (1925). La Géographie humaine (3a ed.) Paris: Félix Alcan.

» Castro, T. (1965). Evolução política e crescimento da cidade do Rio de Janeiro. Revista Brasileira de Geografia, 27(4), 569-586.

»Chiaradia, A. (2019). Urban Morphology/Urban Form. Em A. Orum (Ed.), The Wiley Blackwell Encyclopedia of Urban and Regional Studies (pp. 1-6). Nova Jersey: Wiley-Blackwell.

»Christaller, W. (1966). Central places in Southern Germany. Nova Jersey: PrenticeHall.

» Claval, P. (2012). A paisagem dos geógrafos. Em R. Corrêa Lobato e Z. Rosendahl (Orgs.), Geografia cultural: uma antologia (Vol. 1) (pp. 245-276). Rio de Janeiro: EdUERJ.

»Cosgrove, D. (2012). A geografia está em toda parte: cultura e simbolismo nas paisagens humanas. Em R. Corrêa Lobato e Z. Rosendahl (Orgs.), Geografia Cultural: uma antologia (Vol. 1) (pp. 219-237). Rio de Janeiro: EdUERJ.

»Davies, A. (1933). A study in city morphology and historical geography. Geography, 18(1), 25-37.

» Dickinson, R. (1934). The Town Plans of East Anglia. A study in urban morphology. Geography, 19(1), 37-50.

»Fleure, H. (1920). Some types of cities in temperate Europe. The Geographical Review, 10(6), 357-374.

»Frias, R. e Machado, A. (2019). Escuchar la ciudad: sonido y sociabilidad. Em P.C. Gomes e L. Parente-Ribeiro (Orgs.), Formas de la Sociabilidad. Una geografía de los espacios públicos en Río de Janeiro (pp. 169-188). Granada: Editorial Universidad de Granada. 
0 espaço, o drama: vida pública e... RAFAEL Augusto ANDRADE Gomes

»Frolov, Y.S. (1975). Measuring the shape of geographical phenomea: a history of the issue. Soviet Geography, 16(10), 676-687.

»Geertz, C. (2008). A interpretação das culturas. Rio de Janeiro: LTC.

》 Gehl, J. (1987). Life between buildings: using public space. Nova York: Van Nostrand Reinhold.

》 Geiger, P. (1960). Ensaio para a estrutura urbana do Rio de Janeiro. Revista Brasileira de Geografia, 22(1), 3-46.

» Genette, G. (1987). Seuils. Paris: Seuil.

» Goffman, E. (2016). La diversión de los juegos. Apuntes de Investigación del CECYP, 28, 12-67.

》 Góis, M.P. (2008). A geografia em quadrinhos: uma análise dos elementos sócioespaciais que compõem a imagem da cidade no universo quadrinhográfico. Trabalho de Conclusão de Curso (Graduação em Geografia) - Universidade Federal do Rio de Janeiro, Rio de Janeiro.

» Góis, M.P. (2017). Paisagens luminosas e cenários noturnos: formas, práticas e significados da noite na cidade do Rio de Janeiro. Niterói, RJ: Editora da Universidade Federal Fluminense.

》 Gomes, P.C. (1997). A dimensão ontológica do território no debate da cidadania: o exemplo canadense. Revista Território, 1(2), 43-62.

» Gomes, P.C. (2001a). A condição urbana. Ensaios de geopolítica da cidade. Rio de Janeiro: Bertrand Brasil.

» Gomes, P.C. (2001b). A cultura pública e o espaço. Desafios metodológicos. Em Z. Rosendahl e R. Corrêa Lobato (Orgs.), Religião, identidade e território (pp. 93114). Rio de Janeiro: EdUERJ.

" Gomes, P.C. (2004). 0 silêncio das cidades: os espaços públicos sob ameaça, a democracia em suspensão. Cidades, 2(4), 249-266.

" Gomes, P.C. (2008a). Cenários para a geografia: sobre a espacialidade das imagens e suas significações. Em Z. Rosendahl e R. Corrêa Lobato (Orgs.), Espaço e cultura: pluralidade temática (pp. 187-209). Rio de Janeiro: EdUERJ.

"Gomes, P.C. (2008b). Imagens da cidade e cidades imaginadas: confusões, perigos e desafios. Em M. Oliveira, M.C. Coelho e A. Corrêa (Orgs.), O Brasil, a América Latina e o mundo: espacialidades contemporâneas (II) (pp. 314-330). Rio de Janeiro: Lamparina Editora.

" Gomes, P.C. (2011a). Espaços Públicos: a Cidade em Cena (I). A Fabricação do Filme. O Relato de uma aventura. Espaço Aberto, 1(2), 9-22.

》 Gomes, P.C. (2011b). Espaços Públicos: a Cidade em Cena (II). Modos de Usar, Efeitos Colaterais e Reações Adversas. Espaço Aberto, 1(2), 23-28.

" Gomes, P.C. (2012). Espaços públicos. Em I.E. Castro, P.C. Gomes e R. Corrêa Lobato (Orgs.), Olhares Geográficos. Modos de ver e viver o espaço (pp. 19-42). Rio de Janeiro: Bertrand Brasil.

"Gomes, P.C. (2013). O lugar do olhar: elementos para uma geografia da visibilidade. Rio de Janeiro: Bertrand Brasil.

" Gomes, P.C. (2017). Quadros geográficos. Uma forma de ver, uma forma de pensar. Rio de Janeiro: Bertrand Brasil. 
0 espaço, o drama: vida pública e...

RAfaEl Augusto ANDRADE Gomes

》 Gomes, P.C. (2020). Espaços públicos e territórios. A propósito da reflexão sobre as relações entre espaço e poder. Punto Sur, Revista de Geografía de la UBA, 3, 153169.

" Gomes, P.C. e Góis, M.P. (2008). A cidade em quadrinhos: elementos para a análise da espacialidade nas histórias em quadrinhos. Cidades, 5(7), 17-32.

》 Gomes, P.C. e Parente-Ribeiro, L. (2012). Metodologias visuais e imaginação urbana: uma experiência no Recife. Em C. Maciel, C. Gonçalves, C. e M. Pereira (Orgs.), Abordagens geográficas do agrário e do urbano (pp. 63-73). Recife: Editora Universitária UFPE.

» Gomes, P.C. e Parente-Ribeiro, L. (2013). A produção de imagens para a pesquisa em geografia. Espaço e Cultura, 22, 27-42.

» Gomes, P.C. e Parente-Ribeiro, L. (Orgs.) (2019). Formas de la Sociabilidad. Una geografía de los espacios públicos en Río de Janeiro. Granada: Editorial Universidad de Granada.

》 Grupo de Pesquisa Território e Cidadania (Produtor) (2012). Cenas da Vida Urbana. Espaços Públicos e Cidadania [DVD].

" Hartshorne, R. (1979). Notes toward a bibliobiography of "The Nature of Geography". Annals of the Association of American Geographers, 69(1), 63-76.

» Hiernaux-Nicolás, D. (2019). Prólogo: El espacio público: ¿Guerra y paz? Em P.C. Gomes e L. Parente-Ribeiro (Orgs.). Formas de la Sociabilidad. Una geografía de los espacios públicos en Río de Janeiro (pp. 11-16). Granada: Editorial Universidad de Granada.

» Jacobs, J. (1961). The Death and Life of Great American Cities. Nova York: Random House.

» Jenks, C. (1996). Introduction: The centrality of the Eye in Western Culture. Em C. Jenks, Visual Culture (pp. 1-25). Londres: Routledge.

» Keighren, I. (2010). Bringing geography to book: Ellen Semple and the Reception of Geographical Knowledge. Londres: I. B. Tauris.

» Latour, B. (2015). Cognição e visualização. Pensando com olhos e mãos. Terra Brasilis (Nova Série), Revista da Rede Brasileira de História da Geografia e Geografia Histórica, 4, s/p.

" Ministério da Educação (2006). Orientações curriculares para o Ensino Médio (Vol. 3). Ciências humanas e suas Tecnologias. Brasília: Ministério da Educação, Secretaria de Educação Básica.

» Moisés, M. (2004). Dicionário de termos literários (12a ed.). São Paulo: Editora Cultrix.

》 Monbeig, P. (1940). Ensaios de geografia humana brasileira. São Paulo: Livraria Martins.

》Parente-Ribeiro, L. (2016). A apresentação da espera nos espaços públicos: modos de ocupar, formas de olhar. Nuevo Mundo. Mundos Nuevos. Recuperado de: https://journals.openedition.org/nuevomundo/68946

" Pinto, M. (1965). A cidade do Rio de Janeiro: Evolução física e humana. Revista Brasileira de Geografia, 27(2), 191-232.

»Sack, R. (1986). Human territoriality: its theory and history. Nova York: Cambridge University Press. 
0 espaço, o drama: vida pública e... RAFAEL Augusto ANDRADE Gomes

》Santos, A. (2004). Encenação da vida privada: entrando nos bastidores do espaço público. Trabalho de Conclusão de Curso (Graduação em Geografia), Universidade Federal do Rio de Janeiro, Rio de Janeiro.

»Santos, A. (2007). Espaço público, imagem da cidade. Uma análise geográfica do filme de Eric Rohmer ("O signo do leão", França, 1959). Dissertação (Mestrado em Geografia), Universidade Federal do Rio de Janeiro, Rio de Janeiro.

"Santos, M. (1978). Por uma geografia nova. Da Crítica da Geografia a uma Geografia Crítica. São Paulo: Hucitec.

»Santos, M. (1987). 0 espaço do cidadão. São Paulo: Livraria Nobel S. A.

»Santos, M. (2012). A natureza do espaço. Técnica e Tempo, Razão e Emoção (4a ed.). São Paulo: EdUSP.

"Segadas Soares, M. (1965). Fisionomia e estrutura do Rio de Janeiro. Revista Brasileira de Geografia, 27(3), 329-388.

"Semple, E. (1911). Influences of Geographic Environment, On the Basis of Ratzel's System of Anthropo-Geography. Nova York: Henry Holt and Company - Londres: Constable \& Company LTD.

» Silva, T. (2004). A geografia e o Theatrum Mundi: uma proposta espacial de comparação entre teatro e cidade. Trabalho de Conclusão de Curso (Graduação em Geografia) - Universidade Federal do Rio de Janeiro, Rio de Janeiro.

"Silva, T. (2007). $O$ espetáculo das multidões: manifestações políticas e signos espaciais nos espaços públicos do Rio de Janeiro. Dissertação (Mestrado em Geografia), Universidade Federal do Rio de Janeiro, Rio de Janeiro.

》 Simmel, G. (1983). A natureza sociológica do conflito. Em E. Moraes Filho (Org.), Georg Simmel. Sociologia (pp. 122-134). São Paulo: Editora Ática.

》Simmel, G. (2006). Questões fundamentais da sociologia. Indivíduo e sociedade. Rio de Janeiro: Jorge Zahar Editor.

» Tuan, Y. (1974). Topophilia. A study of environmental perception, attitudes and values. Englewood Cliffs: Prentice Hall.

» Tuan, Y. (1979). Landscapes of Fear. Oxford: Blackwell.

"Valverde, R. (2007). A transformação da noção de espaço público: a tendência à heterotopia no largo da Carioca. Tese (Doutorado em Geografia), Universidade Federal do Rio de Janeiro, Rio de Janeiro.

》Whyte, W. (1943). Street Corner Society. Chicago: University Chicago Press.

"Wright, J.K. (1962). Miss Semple's "Influences of Geographic Environment". Notes toward a Bibliobiography. Geographical Review, 52(1), 346-361.

Rafael Augusto Andrade Gomes / rafagomesgeo@gmail.com

Doutorando do Programa de Pós-Graduação em Geografia da Universidade Federal do Rio de Janeiro e integrante do Grupo de Pesquisa Território e Cidadania. Editor Adjunto da Terra Brasilis (Nova Série), Revista da Rede Brasileira de História da Geografia e Geografia Histórica. Tem experiência na área de geografia, com ênfase em história do pensamento geográfico e teoria da geografia, e desenvolve pesquisas nos seguintes temas: historiografia da ciência geográfica, biografia científica e métodos de pesquisa em história da geografia. 